LA-UR- 664

\title{
Tite: PROBABILITY OF SURVIVAL FROM MULTIPLE WEAPON ATTACKS
}

Author(s):

Gregory H. Canavan, DDP

Submitted to:

For discussions outside the Laboratory

RECEIVED

MAY 051997

OSTI

Date: February 1997
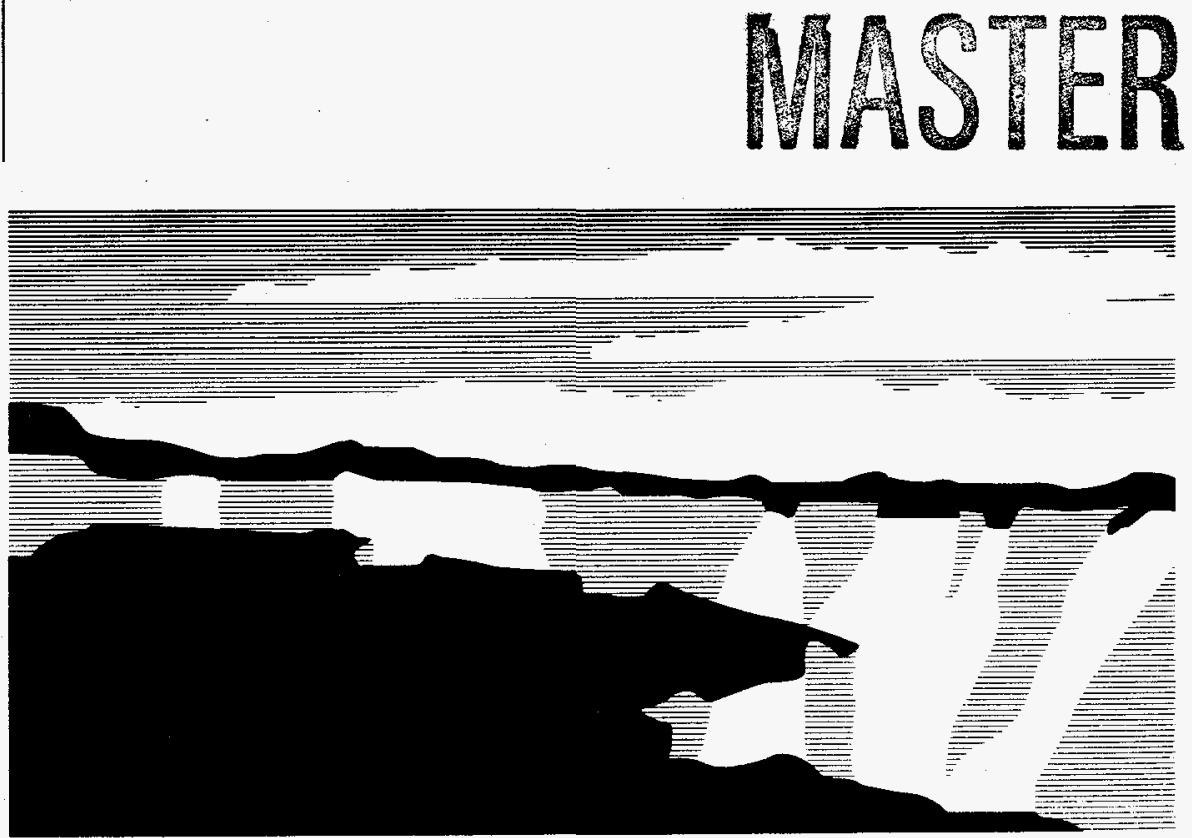

Los Alamos National Laboratory, an affirmative action/equal opportunity employer, is operated by the University of California for the U.S. Department of Energy under contract W-7405-ENG-36. By acceptance of this article, the publisher recognizes that the U.S. Government retains a nonexclusive, royalty-free license to publish or reproduce the published form of this contribution, or to allow others to do so, for U.S. Government purposes. The Los Alamos National Laboratory requests that the publisher identity this article as work performed under the auspices of the U.S. Department of Energy. 


\section{DISCLAIMER}

This report was prepared as an account of work sponsored by an agency of the United States Government. Neither the United States Government nor any agency thereof, nor any of their employees, make any warranty, express or implied, or assumes any legal liability or responsibility for the accuracy, completeness, or usefulness of any information, apparatus, product, or process disclosed, or represents that its use would not infringe privately owned rights. Reference herein to any specific commercial product, process, or service by trade name, trademark, manufacturer, or otherwise does not necessarily constitute or imply its endorsement, recommendation, or favoring by the United States Government or any agency thereof. The views and opinions of authors expressed herein do not necessarily state or reflect those of the United States Government or any agency thereof. 


\section{DISCLAMMER}

Portions of this document may be illegible in electronic image products. Images are produced from the best available original document. 


\title{
PROBABILITY OF SURVIVAL FROM MULTIPLE WEAPON ATTACKS
}

\author{
Gregory H. Canavan
}

Probabillties

Exact and approximateies of missiles surviving attacks by multiple weapons are derived and discuŝsed. Both are readily computable; the exponential approximation is also suited to analytic optimizations.

This note discusses the survival probabilities for multiple weapons missile attacks. It derives analytic and approximate expressions for average survival probabilities. Both are readily computable. The exponential approximation is sufficiently useful for rough calculations and is well suited to analytic optimizations

Model. The probability of survival of a missile silo against the attack of a weapon with a kill probability $\mathrm{p}$ is $\mathrm{q}=1-\mathrm{p}$. The probability of survival against two independent weapons is $\mathrm{q}^{2}$; the probability of survival against weapons is $q^{3}$; etc.

In an attack of $\mathrm{N}$ weapons on $\mathrm{M}$ missiles, the number of weapons per silo will vary from silo to silo. There is an average of $n=N / M$ weapons per silo, but the number of weapons on each silo must be an integer. If the integer part of $n$ is $i=\operatorname{Int}(N / M)$ and the remainder is $r=n-i$, the most efficient allocation of weapons is to place $i+1$ weapons on a fraction $r$ of the silos and $i$ weapons on the remaining $1-r$, which gives an average probability of survival

$$
\mathrm{Q}=\mathrm{rq}^{\mathrm{i}+1}+(1-\mathrm{r}) \mathrm{q}^{\mathrm{i}} \text {, }
$$

which is shown in Fig. 1 as a function of the number of weapons $N$ of kill probability $p=0.6$ and 0.8 for $M=40$ silos. For each value of $p$, the curves fall linearly for $N$ up to 40 , at which each reaches the single coverage values of $Q=1-p$, which are 0.4 and 0.2 , respectively. They again fall linearly with different slopes for $\mathrm{N}$ up to 80 , at which each reaches the single coverage values of $Q=(1-p)^{2}$, which are 0.16 and 0.04 , respectively. These values of $p$ and the N/M of $1 / 4$ to 2 roughly bound the attacks of interest.

The approximate probability of survival can be bounded by treating the number of weapons per silo, $r$, to be a fraction, which gives an approximate average probability of survival

$$
\mathrm{Q}^{\prime}=\mathrm{q}^{\mathbf{r}} \text {, }
$$

which is shown and compared with $Q$ in Fig. 2. The piecewise linear curves are those from Fig. 1. The smooth curves are from Eq. (2). As expected, the differences between them are small for large $N / M$, where the error introduced by treating $r$ as continuous should be small. The approximation is exact at $\mathrm{N}=40$ and 80 , i.e., $\mathrm{r}=1$, and 2 . The error is greatest for $\mathrm{N}$ small and $\mathrm{p}$ large, where it is about $10-20 \%$. There $i=0, r=N / M$, and

$$
\mathrm{Q}(\mathrm{r}<1)=(\mathrm{N} / \mathrm{M})(1-\mathrm{p})+(1-\mathrm{N} / \mathrm{M}) \mathrm{q}^{0}=1-(\mathrm{N} / \mathrm{M}) \mathrm{p},
$$

while 


$$
\mathrm{Q}^{\prime}=(1-\mathrm{p})^{\mathrm{N} / \mathrm{M}} \text {, }
$$

which only agrees with $Q$ to first order. Between the integer values of r, for which it is exact, $Q^{\prime}$ always lies below $Q$. so $Q$ ' always underestimates the survival probability by a modest extent.

Summary and conclusions. This note discusses the survival probabilities for multiple weapons missile attacks. It derives analytic and approximate expressions for average survival probabilities. Both are readily computable. The exponential approximation is sufficiently useful for rough calculations and is well suited to analytic optimizations. 


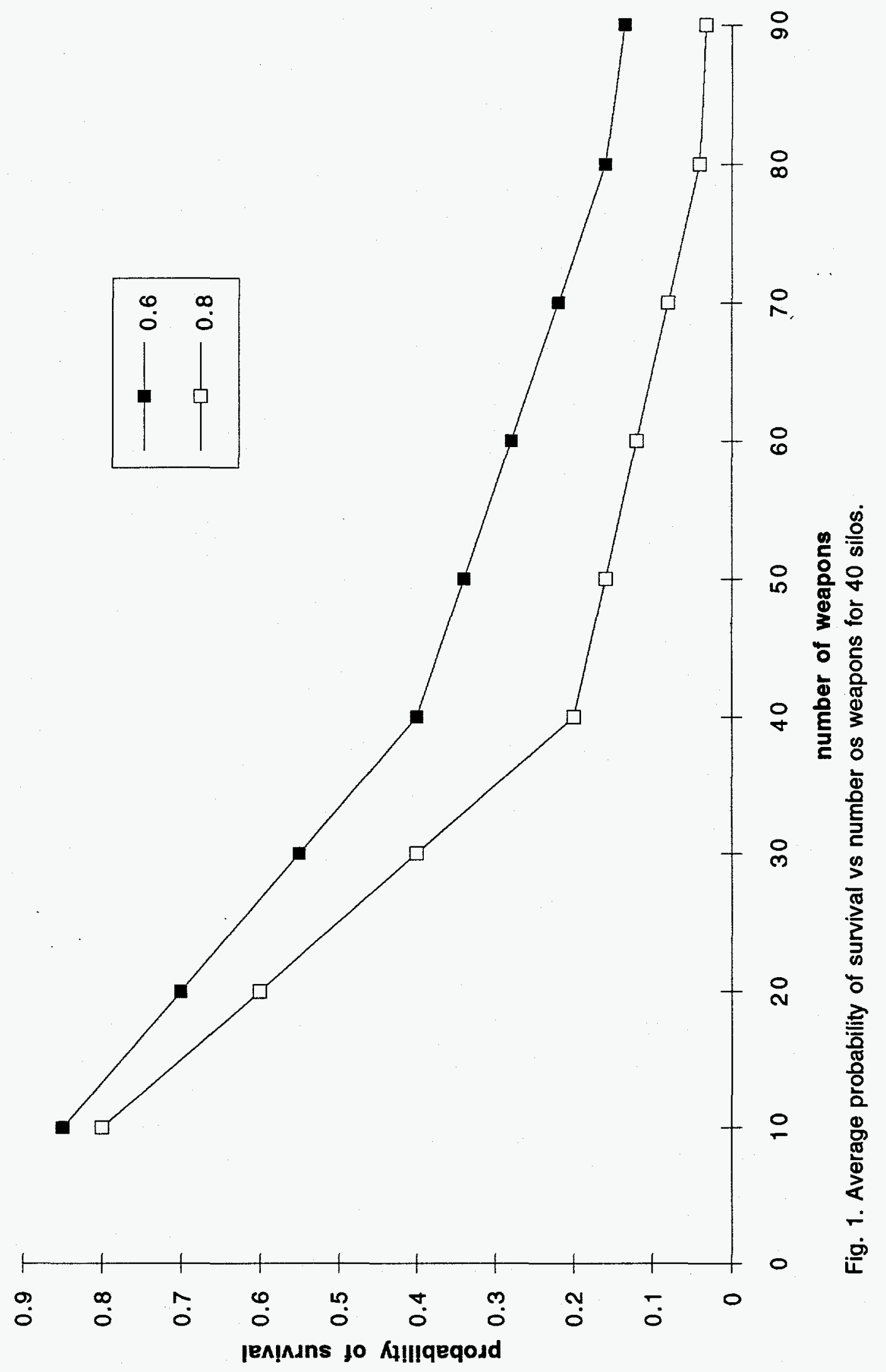




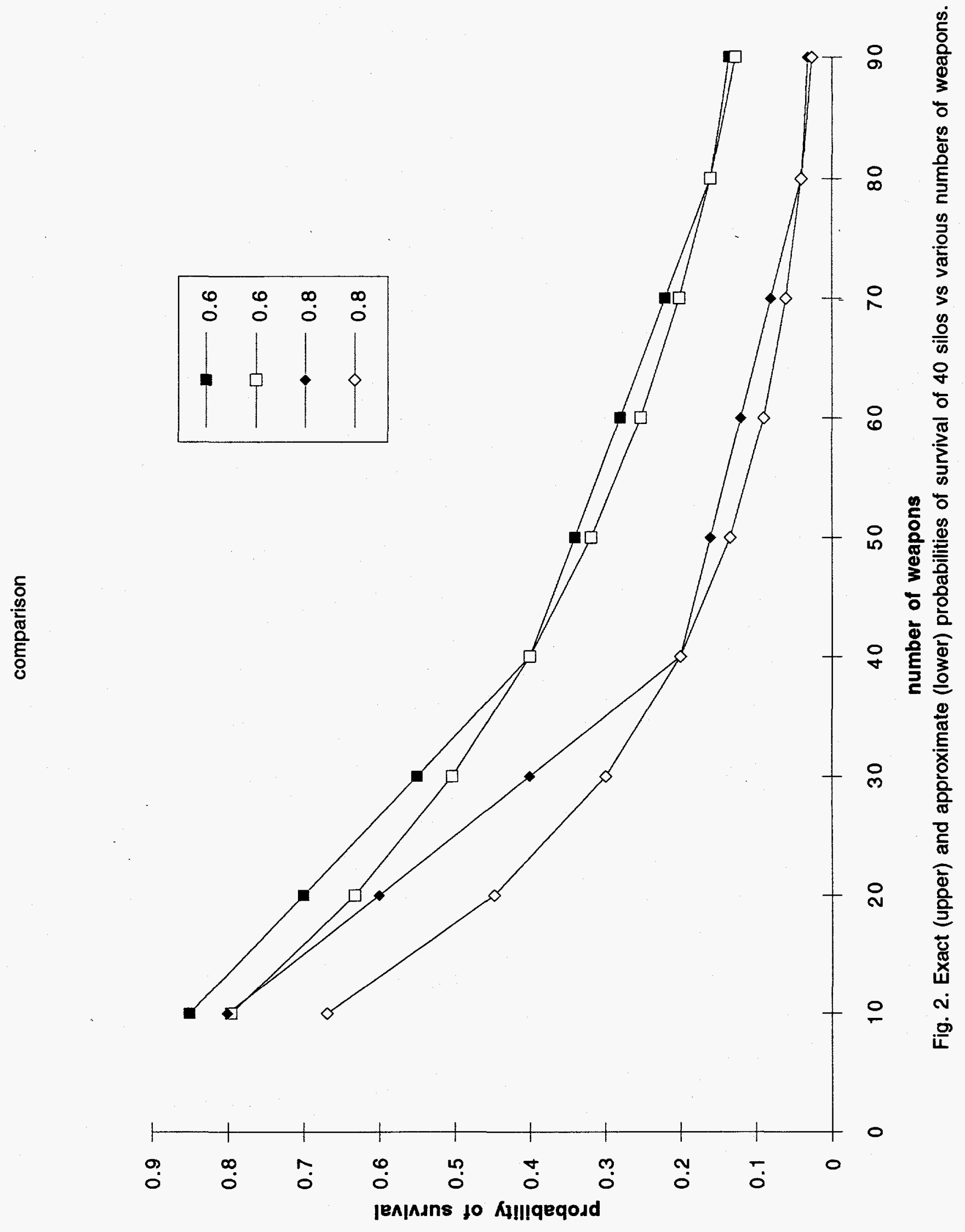

